Tohoku J. exp. Med., 1988, 156, 375-379

\title{
Nuclear Deformity of Hepatocytes in Acute Viral Hepatitis
}

\author{
Tomoyuki Masuda, Ryoichi Satodate, Kazuyuki \\ SuzUkI* and ShUnichi SATO* \\ Department of Pathology and *Department of Internal \\ Medicine, School of Medicine, Iwate Medical University, \\ Morioka 020
}

\begin{abstract}
Masuda, T, Satodate, R., Suzuki, K. and Sato, S. Nuclear Deformity of Hepatocytes in Acute Viral Hepatitis. Tohoku J. exp. Med., 1988, 156 (4), 375-379 - Nuclear deformity of hepatocytes was measured using two parameters, the form factor and the axial ratio, in liver biopsy specimens from 29 patients with acute viral hepatitis (AVH). Another 13 patients with chronic persistent hepatitis (CPH) were added as control. Nuclear deformity of hepatocytes was morphometrically confirmed to increase in AVH compared to that in CPH. This was related to the regeneration of hepatocytes. —_ acute viral hepatitis; morphometry; image analysis; nuclear deformity
\end{abstract}

Nuclear deformity and anisokaryosis of hepatocytes are two characteristic features seen in acute viral hepatitis $(\mathrm{AVH})$. We have already made a morphometric study and confirmed a wide variation in the nuclear area of hepatocytes in AVH as compared with chronic persistent hepatitis (CPH) (Masuda et al. 1988). The purpose of the present study is to analyze the shape changes of hepatocytic nuclei in AVH.

\section{Materials and Methods}

\section{Materials}

The liver biopsy specimens were obtained from 29 patients who were clinically diagnosed as having AVH (Fig. 1a). Of the 29 cases, 7 were confirmed to have hepatitis A, 6 bepatitis $B$ and the others were thought to have non-A, non-B hepatitis. Patients with other hepatotoxic viral infections and drug-induced hepatitis were excluded. Biopsies were performed within 3 months (12-90 days) after the onset. Another series of biopsy specimens from 13 patients with CPH (de Groote et al. 1968) having little parenchymal damage was also examined in the same way and served as control (Fig. lb). All patients with CPH were hepatitis B surface antigen carriers. Specimens were taken under laparoscopy using a $1.8 \mathrm{~mm}$-sized Silverman needle.

Specimens were fixed in a $15 \%$ formalin solution, dehydrated in a series of alcohol, and embedded in paraffin. Sections were cut at $3 \mu \mathrm{m}$ in thickness and were stained by the

Received August 23, 1988; revision accepted for publication October 28, 1988.

Mailing address: Tomoyuki Masuda, M.D., Department of Pathology, School of Medicine, Iwate Medical University, Uchimaru 19-1, Morioka 020, Japan. 


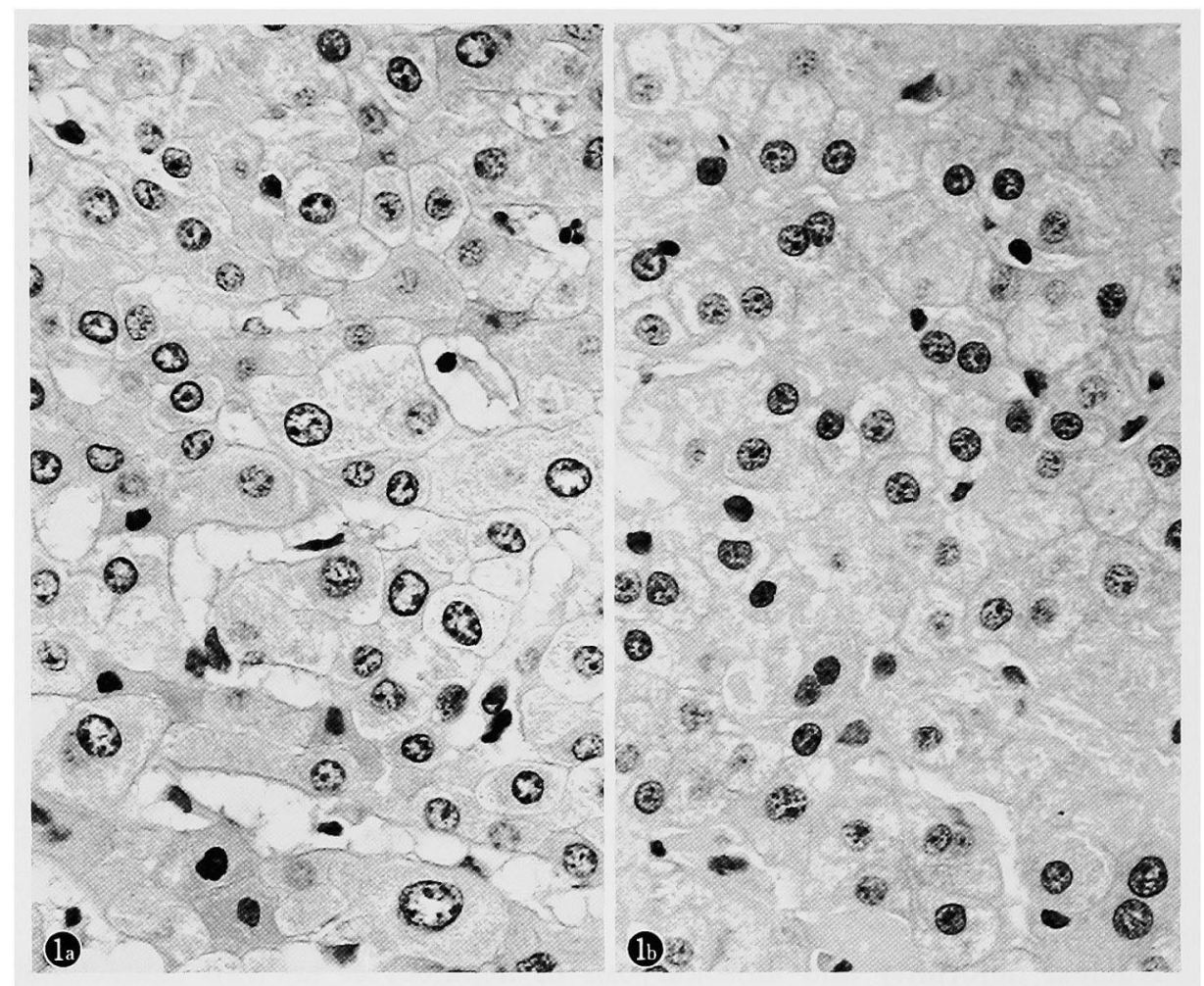

Figs. la and b. Microscopic features of hepatocytes in AVH (a) and CPH (b). It is easily seen in the figures that nuclear area is lager in AVH than in CPH. In addition, nuclei in AVH show a wide variation in size as compared with those in $\mathrm{CPH}$. However, it is difficult to decide the degree of nuclear deformity by only impression (H.-E.). $\times 450$.

Feulgen method as follows. The sections were hydrolyzed with $1 \mathrm{~N} \mathrm{HCl}$ at $60^{\circ} \mathrm{C}$ for $12 \mathrm{~min}$ and stained with Schiff's reagent for $2 \mathrm{hr}$.

\section{Measurement}

Histological images were transmitted to an image analyzer (IBAS-2000, Zeiss, Oberkochen, FRG) through a color TV camera (ITC-350 M, Ikegami, Hamamatsu). The graphic display of this analyzer consisted of 512 by 512 picture elements (pixels), and the interval between two adjacent pixels was equivalent to $0.127 \mu \mathrm{m}$ in a microscopic slide. Then the nuclear profiles projected on the display were processed into binary images relying on a combination of techniques including the specific gray threshold level, erosion and dilation operations (Joyce-Loebl 1985). Nuclear area (A), perimeter length (P), and the shortest and the longest diameters ( $\mathrm{S}$ and $\mathrm{L}$, respectively) were measured, then the form factor (FF) and axial ratio (AR) were computed in order to evaluate the degree of nuclear deformity (Gschwind et al. 1986). FF was calculated by $4 \cdot \pi \cdot A / P^{2}$, and AR by $\mathrm{S} / \mathrm{L}$ (Fig. 2 ). In each patient, 201 to 247 hepatocytic nuclei were measured through this procedure.

\section{Statistical analysis}

After examining whether the distribution of $\mathrm{FF}$ and that of $\mathrm{AR}$ can be assumed to be normal, the mean (M) and the coefficient of variation (CV) of FF and AR were computed in each case. $\mathrm{CV}$ was calculated by $\mathrm{SD} / \mathrm{M} \times 100$, where $\mathrm{SD}$ was the standard deviation. 


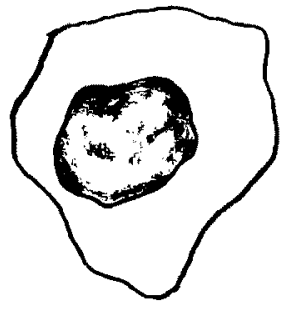

a

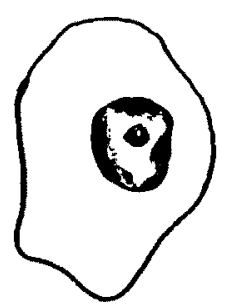

b

Nuclear measurement

$$
\text { a: } \begin{aligned}
& \mathrm{A}=139.0 \mathrm{~mm}^{2}, \mathrm{P}=48.0 \mathrm{~mm}, \mathrm{FF}=0.76 \\
& \mathrm{~S}=12.2 \mathrm{~mm}, \mathrm{~L}=15.5 \mathrm{~mm}, \mathrm{AR}=0.79 \\
& \text { b: } \mathrm{A}=60.7 \mathrm{~mm}^{2}, \quad \mathrm{P}=30.3 \mathrm{~mm}, \mathrm{FF}=0.83 \\
& \mathrm{~S}=8.1 \mathrm{~mm}, \quad \mathrm{~L}=9.6 \mathrm{~mm}, \mathrm{AR}=0.85
\end{aligned}
$$

Fig. 2. Schematic illustration for the form factor $(F F)$ and the axial ratio $(A R)$ of nuclei. $a$ is a hepatocyte in $\mathrm{AVH}$, and $b$ is that in CPH. Magnification was about 1000 times.

Ms and $\mathrm{CV}_{\mathrm{s}}$ of $\mathrm{FF}$ and $\mathrm{AR}$ in $\mathrm{AVH}$ were compared with those in $\mathrm{CPH}$ by the Student's $t$-test.

\section{RESULtS}

\section{Ms of $F F$ and $A R$}

The mean, $\mathrm{M}$, of the form factor, $\mathrm{FF}$, in $\mathrm{AVH}$ was $0.818 \pm 0.014$ (mean \pm s.D.) and $0.832 \pm 0.013$ in $\mathrm{CPH}$; the differences between the means proved to be significant at $p<0.01$ (Fig. 3). The $\mathrm{M}$ of axial ratio, $\mathrm{AR}$, was $0.785 \pm 0.029 \mathrm{in}$ $\mathrm{AVH}$, and $0.811 \pm 0.021 \mathrm{in} \mathrm{CPH}$. The $\mathrm{M}$ of AR was also significantly $(p<0.05)$
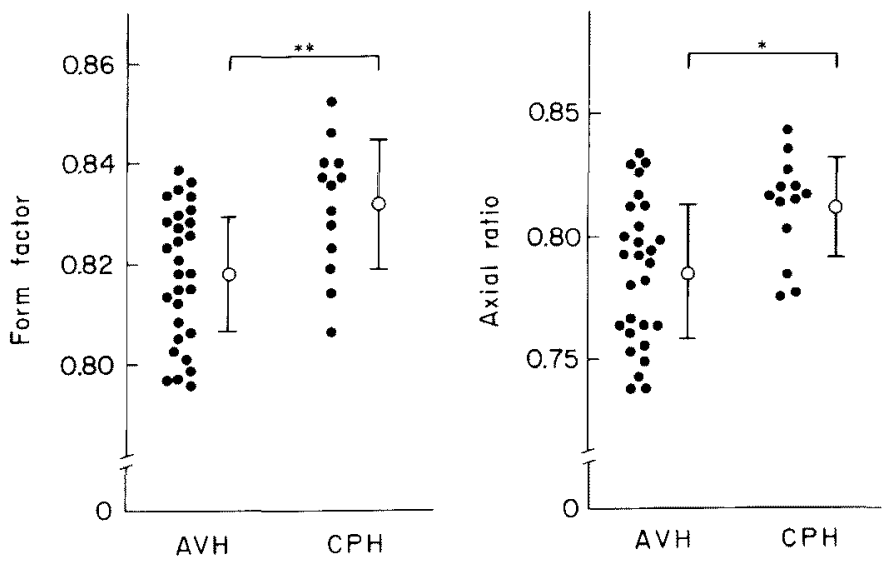

Fig. 3. Means of form factor and axial ratio. - mean of each case; $c$, mean of each group; bar, standard deviation in each group. ${ }^{*} p<0.05 ;{ }^{* *} p<0.01$. 

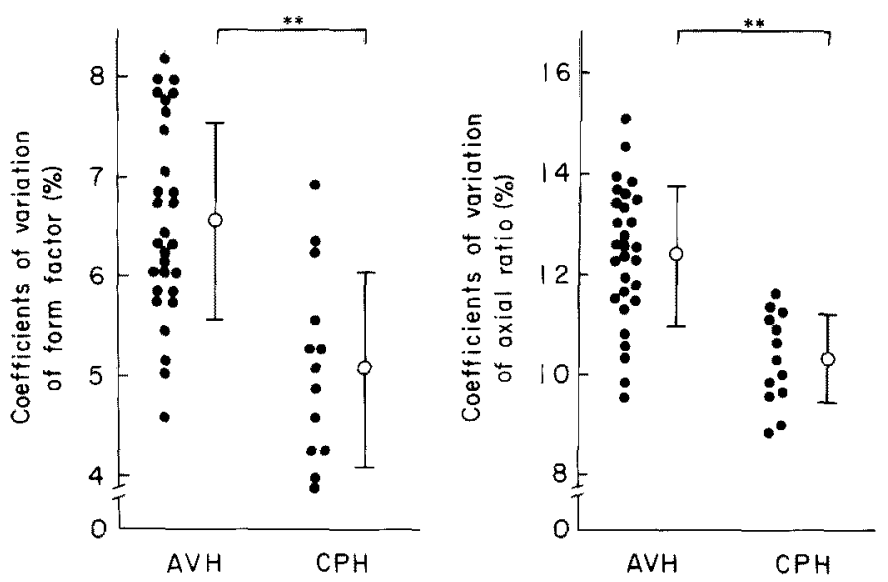

Fig. 4. Coefficients of variation of form factor and axial ratio. $\bullet$, coefficient of variation of each case; 0 , mean of each group; bar, standard deviation in each group. ${ }^{* *} p<0.01$.

smaller in AVH than in CPH (Fig. 3). These results show that hepatocytic nuclei in $\mathrm{AVH}$ are irregular in their form as compared with those in $\mathrm{CPH}$.

$C V$ s of $F F$ and $A R$

The coefficient of variation, $\mathrm{CV}$, of $\mathrm{FF}$ in $\mathrm{AVH}$ was $6.56 \pm 0.99 \%$ and that in $\mathrm{CPH}$ was $5.14 \pm 1.98 \%$. A significant difference $(p<0.01)$ stood between AVH and $\mathrm{CPH}$ (Fig. 4). The $\mathrm{CV}$ of $\mathrm{AR}$ in $\mathrm{AVH}$ was $12.5 \pm 1.4 \%$, and that in $\mathrm{CPH}$ was $10.3 \pm 0.9 \%$. The CV of AR was significantly $(p<0.01)$ larger in AVH than in $\mathrm{CPH}$ (Fig. 4). These results show that hepatocytic nuclei in AVH are notable in their pleomorphism.

\section{Discussion}

Roholm and Iversen (1939) first investigated morphological changes of AVH in biopsy materials and described the nuclei in $\mathrm{AVH}$ as being unequal in size and irregular in form. Although pointed out by many investigators in descriptive morphological terms, this has hardly been confirmed by morphometry of nuclear areas or nuclear deformities. In 1975, Ranek et al. (1975) first measured the nuclear diameter in AVH by a projection method and confirmed the presence of anisokaryosis in AVH. We have also performed a morphometric study of anisokaryosis using an image analyzer (Masuda et al. 1988). However, no morphometric report is found on the nuclear deformity in AVH. In viral hepatitis, quantification of the nuclear deformity is usually more difficult than that of the nuclear area.

The FF is also called "shape factor" or "roundness factor" in other words. The maximal FF value is 1 and indicates a perfect circle. An increasing irregularity, as expressed by the remoteness from the circular form, yields a decreasing 
value (Fig. 2). The AR value reaches the maximal value of 1 when the shortest and the longest axes are equal (Fig. 2). Both parameters have been used for describing the grade of deformity in quantitative morphological analysis (Gschwind et al. 1986; Payne et al. 1987).

In this study it has been confirmed by morphometry that nuclei in AVH are irregular in form as compared with those in CPH. A wide variation in nuclear form in AVH has also been evident. The FF value is in a decreasing tendency in liver cell dysplasia (Henmi et al. 1985), and Watanabe et al. (1983), who classified the dysplastic cells into the large and small cell types, reported that the nuclear ultrastructure of the large dysplastic cells exhibits the features of regeneration. Furthermore, an increased irregularity of nuclei was observed in regeneration after partial hepatectomy in rats (Tauchi and Sato 1962). From these findings, it may be considered that the irregularity of hepatocytic nuclei in AVH is a morphological expression of regenerating hepatocytes.

\section{Acknowledgments}

This work was supported in part by a Grant-in-Aid from the Keiryokai Research Foundation (No. 57, 1987).

\section{References}

1) de Groote, J., Desmet, V.J., Gedigk, P., Korb, G., Popper, H., Poulsen, H., Scheuer, P. J., Schmid, M., Thaler, H., Uehlinger, E. \& Wepler, W. (1968) A elassification of chronic hepatitis. Lancet, 2, 626-628.

2) Gschwind, R., Umbricht, C.B., Torhorst, J. \& Oberholzer, M. (1986) Evaluation of shape descriptors for the morphometric analysis of cell nuclei. Path. Res. Pract., 181, 213-222.

3) Henmi, A., Uchida, T. \& Shikata, T. (1985) Karyometric analysis of liver cell dysplasia and hepatocellular carcinoma: Evidence against precancerous nature of liver cell dysplasia. Cancer, 55, 2594-2599.

4) Joyce-Loebl (1985) Image processing. In : Image Analysis : Principles and Practice, Joyce Loebl, Gateshead, pp. 84-122.

5) Masuda, T., Madarame, T., Abe, K., Suzuki, A., Sato, S., Iwasaki, T. \& Satodate, R. (1988) Karyometric study of anisokaryosis of hepatocytes in acute viral hepatitis. In: Viral Hepatitis and Liver Disease, edited by A.J. Zuckerman, Alan R. Liss Inc., New York, pp. 190-191.

6) Payne, C.M., Grogan, T.M., Cromey, D.W., Bjore, C.G., Jr. \& Kerrigan, D.P. (1987) An ultrastructural morphometric and immunophenotypic evaluation of Burkitt's and Burkitt's-like lymphomas. Lab. Invest., 57, 200-218.

7) Ranek, L., Jensen, S.T. \& Keiding, N. (1975) Karyometry of liver biopsies in virus hepatitis. Acta path. microbiol. scand., A83, 477-486.

8) Roholm, K. \& Iversen, P. (1939) Changes in the liver in acute epidemic hepatitis (catarrhal jaundice) based on 38 aspiration biopsies. Acta path. microbiol. scand., 16, $427-442$.

9) Tauchi, H. \& Sato, T. (1962) Some micromeasuring studies of hepatic cells in senility. $J$. Geront., 17, 254-259.

10) Watanabe, S., Okita, K., Harada, T., Kodama, T., Numa, Y., Takemoto, T. \& Takahashi, T. (1983) Morphologic studies of the liver cell dysplasia. Cancer, 51, 2197-2205. 